\title{
Risk factors for progressive sarcopenia 6 months after complete resection of lung cancer: what can thoracic surgeons do against sarcopenia?
}

\author{
Masashi Nagata ${ }^{1,2,3}$, Hiroyuki Ito ${ }^{1}$, Tetsuo Yoshida ${ }^{4}$, Akihiro Tokushige ${ }^{3}$, Shinichiro Ueda ${ }^{3}$, \\ Tomoyuki Yokose ${ }^{5}$, Haruhiko Nakayama ${ }^{1}$ \\ ${ }^{1}$ Department of Thoracic Surgery, Kanagawa Cancer Center, Asahi-ku, Yokohama, Japan; ${ }^{2}$ Department of General Surgery, Okinawa Kyodo \\ Hospital, Naha, Japan; ${ }^{3}$ Department of Clinical Research and Quality Management, Graduate School of medicine, University of The Ryukyus, \\ Nishihara-cho, Okinawa, Japan; ${ }^{4}$ Department of Diagnostic and Interventional Radiology, ${ }^{5}$ Department of Pathology, Kanagawa Cancer Center, \\ Asahi-ku, Yokohama, Japan \\ Contributions: (I) Conception and design: M Nagata, A Tokushige, S Ueda; (II) Administrative support: H Ito, H Nakayama; (III) Provision of \\ study materials or patients: H Ito, T Yoshida, T Yokose, H Nakayama; (IV) Collection and assembly of data: M Nagata; (V) Data analysis and \\ interpretation: All authors; (VI) Manuscript writing: All authors; (VII) Final approval of manuscript: All authors. \\ Correspondence to: Masashi Nagata. Department of General Surgery, Okinawa Kyodo Hospital, 4-10-55 Kohagura, Naha 900-8558, Japan. \\ Email: masashin6@gmail.com.
}

Background: Our previous report described how postoperative progression of sarcopenia predicted longterm prognosis after complete resection of non-small cell lung cancer (NSCLC) in heavy smokers. However, there are currently no effective means to treat progressive sarcopenia. In this study, we aimed to confirm our previous findings in a larger population and to identify factors associated with postoperative progression of sarcopenia to propose possible preventative measures.

Methods: This retrospective study analyzed the data of 1,095 patients who underwent curative lobar resection for NSCLC at Kanagawa Cancer Center. We divided patients into four groups according to sex and Brinkman index (BI) above or below 600. Six-month postoperative changes in the skeletal muscle index (SMI) were calculated and associations between clinicopathological factors including changes in SMI and mortality from postoperative 6 months were examined. Only in groups in which postoperative depletion of SMI was shown to be associated with the prognosis, we identified clinicopathological factors associated with depletive SMI.

Results: The overall survival rates of 1,095 patients were $89.8 \%$ and $82.5 \%$ at 3 and 5 years, respectively. The median 6-month change in SMI was $-3.4 \%$ (range, $-22.3 \%$ to $+17.9 \%$ ). Multivariate analysis revealed that poor prognosis was independently predicted by a large reduction in the SMI (cut-off value: $-10 \%$ ) in males with a $\mathrm{BI} \geq 600$. In 391 heavy-smoking males, factors associated with a postoperative change in SMI $\leq-10 \%$ were history of other cancers (including gastric cancer) low forced expiratory volume in one second (FEV 1.0, cut-off value: 1,870 mL), and prolonged operation time (cut-off value: 200 minutes).

Conclusions: Perioperative measures to prevent postoperative sarcopenia are appropriate for heavy smokers. We obtained some clues regarding countermeasures, one of which may be avoiding long-time operation. Further studies including clinical trials to assess perioperative anti-sarcopenia treatments, are needed.

Keywords: Lung cancer; surgery; chronic obstructive pulmonary disease (COPD); gastric cancer; operation time

Submitted Oct 29, 2019. Accepted for publication Dec 20, 2019.

doi: $10.21037 /$ jtd.2020.01.44

View this article at: http://dx.doi.org/10.21037/jtd.2020.01.44 


\section{Introduction}

Sarcopenia is reportedly a poor prognostic factor following treatment for various diseases, including advanced cancer, chronic obstructive pulmonary disease (COPD), and cardiac disease (1-3). Low muscle mass is an essential element of sarcopenia and cachexia, defined as sarcopenia induced by affecting diseases. Recently, computed tomography (CT) has been more frequently used especially in cancer patients, and there have been attempts to assess muscle mass using CT images such as a skeletal muscle index (SMI), defined as skeletal muscle area (SMA) at the third lumbar vertebra (L3) on CT divided by the patient's height in meters squared (4). A low SMI is associated with poor prognosis in various cancers, not only in advanced stages (5-7), but also after curative resection (8-12).

Preoperative sarcopenia can be estimated using particular cut-off values of the SMI or the psoas muscle index (calculated in the same way as the SMI but only referring to the psoas muscle) and it has represented a longterm prognostic factor in patients with resected non-small cell lung cancer (NSCLC) (10-13). Nevertheless, these studies have only demonstrated that sarcopenia is a risk factor for poor prognosis and may not suggest the actions to take based on the results. We reported that reduction in the SMI during the 6 months following complete resection of NSCLC is a significant prognostic factor after the postoperative 6-month follow-up, especially in heavy smokers (14). These results could justify acting to prevent postoperative progression of sarcopenia after curative resection of lung cancer for heavy smokers, although there is no current treatment for sarcopenia that has been demonstrated to improve long-term prognosis (6,15-17). In our previous study, we did not analyze risk factors associated with postoperative sarcopenia because of the limited number of patients for the analysis.

In this study, involving a larger population, we again confirmed the postoperative decline in the SMI could predict the poor prognosis after postoperative period, especially in heavy smokers. Moreover, we identified factors associated with postoperative reduction of the SMI so as to suggest possible measures for preventing perioperative sarcopenia. One study reported that postoperative 1-year decreases in SMI at the 12th thoracic vertebra level were significantly associated with poor prognosis in 100 patients after complete resection of stage I lung cancer (18) and that both performance status (PS) $\geq 1$ and obstructive ventilatory impairment were associated with the postoperative 1-year decrease. There have been no other similar reports to date.

\section{Methods}

A total of 1,277 patients underwent lobectomy (excluding bilobectomy and pneumonectomy) with no evidence of pathological residual cancer for NSCLC at the Kanagawa Cancer Center between 2007 and 2014. We excluded 25 patients due to previous lung resection, 16 patients who died within the postoperative 6 months, and 34 patients who experienced recurrence within postoperative 6 months. Anonymized data for 1,102 patients were available for calculating the 6-month postoperative change of the SMI. We excluded five patients due to postoperative bronchopleural fistula and two patients due to postoperative acute respiratory distress syndrome, as these diseases could affect postoperative SMI considerably. This retrospective study therefore analyzed data from 1,095 patients. No other inclusion or exclusion criteria were applied. The study's protocol complied with the Declaration of Helsinki and was approved by our institutional review board (ID 2018-103). The need for patient consent was waived because all data in this study were completely anonymized.

Medical records were analyzed to determine changes in SMI and survival outcomes. The associations of the changes in the SMI and survival outcomes with patients' clinicopathological characteristics, obtained immediately before surgery, were evaluated using multivariate analyses.

Based on the previous study, we hypothesized that postoperative sarcopenia was associated with the prognosis only in heavy-smoking patients. In addition, analyses using variables related to the absolute value of muscle mass like SMI should be performed separately for males and females because the distribution of SMI differs for each sex. First, we divided 1,095 patients into four groups based on sex and Brinkman index (BI) values $\geq 600$ or $<600$ and analyzed the association between the distribution of SMI changes across the six postoperative months and the long-term prognosis thereafter in each of the four groups. Next, for the group in which postoperative depletion of SMI was shown to be associated with long-term prognosis, we determined the cut-off value for the rate of change of SMI and investigated whether postoperative reduction in SMI correlated with any perioperative clinicopathological factors and operative factors.

Details of the operative procedure, postoperative followup, and definition of recurrence were reported previously (14). Most patients underwent video-assisted surgery with 10 to $15 \mathrm{~cm}$ posterolateral incision during the lobectomy. However, the incisions were changed according to any additional procedures to be performed, for example, 
sleeve resection. No patient was treated using complete thoracoscopic surgery. We performed systematic hilar and mediastinal lymph node dissection according to the lymph node map presented by the International Association for the Study of Lung Cancer (19). In case of no clinical findings of lymph node metastasis (cN0), the upper mediastinal lymph nodes were systematically dissected for tumors located in the upper lobes; lymph nodes were dissected for tumors in the lower lobes. In the presence of clinical findings of lymph node metastasis ( $\mathrm{cN} 1$ or 2 ) or of tumors in the middle lobe with cN0-2, both upper and lower mediastinal lymph nodes were systemically dissected. However, based on the clinical or surgical stage and the patient's comorbidities, the range of lymph node dissection could be reduced to systematic hilar lymph node dissection or non-systematic lymph node sampling. Postoperative follow-up was conducted every 3 months for the first 2 years, every 6 months during the subsequent 2 years, and then annually thereafter. Recurrence was diagnosed pathologically via biopsy or clinically based on the presence of nodules that increased in size as assessed by CT or brain magnetic resonance imaging (MRI) with accumulation of 2-[18]-fluoro-2-deoxy-Dglucose during positron-emission tomography (FDG-PET). The lung cancer board at our institution officially diagnosed all cases.

\section{Calculating changes in SMI based on CT images}

SMI changes were calculated as described previously (14). We changed only the application used for calculation. SMIs before and 6 months postoperatively were determined using plain CT slices with 5 -mm intervals. There was no standardized protocol or parameters for CT imaging. As indicated by previous reports, the abdominal and paraspinal muscles in an axial image at L3 can be identified using boundaries of -29 to +150 Hounsfield units (4-6,20). We routinely checked and manually corrected these boundaries on the CT images. The crosssectional muscle areas were subsequently calculated using image analysis software (Slice-O-Matic ${ }^{\circledR}$ v5.0 rev8; Tomovision, Montreal, Canada). The average of the cross-sectional areas from the two adjacent images was defined as the SMA $\left(\mathrm{cm}^{2}\right)$, and the SMI was calculated as SMA/height ${ }^{2}\left(\mathrm{~cm}^{2} / \mathrm{m}^{2}\right)$. The 6 -month postoperative change in SMI (\%) was calculated as [(postoperative SMI - preoperative SMI)/preoperative SMI] $\times 100$. A single investigator (Masashi Nagata) who was blinded to the patients' outcomes performed these analyses. Preliminary measurements of intra- and inter-observer coefficients of variation were performed by two trained measurers (radiological technicians) using 100 patients chosen randomly from our cohort. Intra-observer and interobserver variability was $1.49 \%$ and $1.76 \%$, respectively, which were not inferior to those of previous reports $(21,22)$ though statistical assessment was impossible.

\section{Statistical analysis}

Categorical and continuous variables that were significantly associated with survival on univariate analyses were included in the multivariate analysis, which was performed using a Cox proportional hazards model for survival or a logistic regression analysis for categorical variables constructed using the stepwise method. In the multivariate analyses, we confirmed there were no significant interactions between the variables. The cut-off value was determined using the maximum Youden's index value on the receiver operating characteristic (ROC) curve. Survival curves were created using the Kaplan-Meier method. All tests were two-sided, and differences were considered statistically significant with $\mathrm{P}$ values of $<0.05$. All statistical analyses were performed using the JMP software package (version 12.1.0; SAS Institute, Cary, NC, USA).

\section{Results}

\section{Postoperative prognosis and 6-month changes in SMI in the four groups}

The median follow-up period from 6 months after the operation was 55.9 months (range, 1.5-121 months). Follow-up was discontinued for 31 patients $(2.8 \%)$. The overall survival rates of all 1,095 patients were $89.8 \%$ and $82.5 \%$ at 3 and 5 years, respectively. Figure 1 shows the overall survival curves of the four groups. Among heavy smokers, there were substantially more males $(n=391)$ than females $(n=34)$. Therefore, we excluded heavy-smoking females from the study. The long-term prognosis of heavy smokers was significantly worse than that of non-heavy smokers. Table 1 presents the preoperative body mass index (BMI), preoperative SMI, postoperative SMI, the change of SMI in univariate analysis of the association with survival from postoperative 6 months in each of the four groups. In univariate and multivariate analyses, non-heavy-smoking males and females did not show any association between changes in SMI and long-term mortality (Tables S1-S3). 


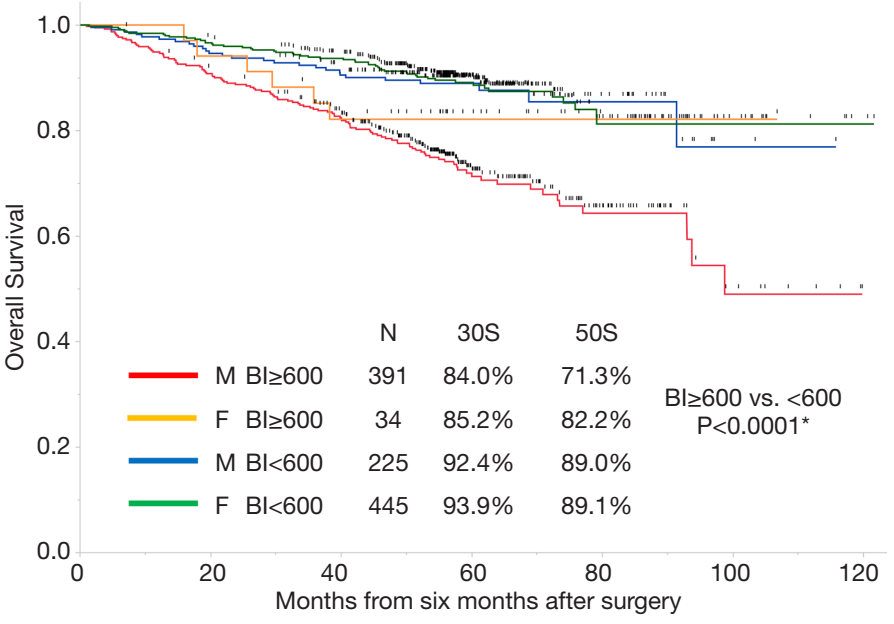

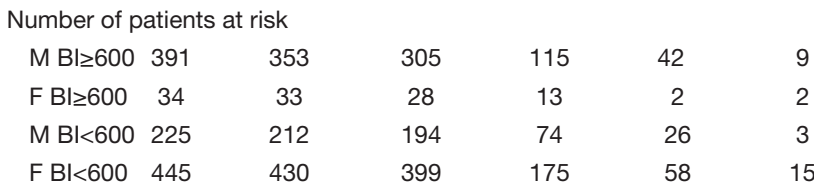

Figure 1 Overall survival of the four groups. N, number; M, male; F, female; BI, Brinkman index; 3OS, 3-year overall survival; 5OS, 5-year overall survival; P values, Log-rank test, *, statistically significant.

Table 1 Association of body mass index and skeletal muscle index with survival from postoperative six months in the four groups

\begin{tabular}{|c|c|c|c|c|}
\hline Variables & $\begin{array}{l}\text { Males with } \mathrm{BI} \geq 600 \\
\qquad(\mathrm{~N}=391)\end{array}$ & $\begin{array}{l}\text { Males with } \mathrm{BI}<600 \\
\qquad(\mathrm{~N}=225)\end{array}$ & $\begin{array}{l}\text { Females with } \mathrm{BI} \geq 600 \\
\qquad(\mathrm{~N}=34)\end{array}$ & $\begin{array}{l}\text { Females with } \mathrm{Bl}<600 \\
\qquad(\mathrm{~N}=445)\end{array}$ \\
\hline Preoperative BMI $\left(\mathrm{kg} / \mathrm{m}^{2}\right)^{\mathrm{a}}$ & $22.8(15.2-33.3)$ & $22.8(15.5-33.9)$ & $20.9(16.9-34.5)$ & $21.8(14.4-33.7)$ \\
\hline $\mathrm{HR}^{\mathrm{c}}$ & $0.93(0.87-0.99)$ & $0.97(0.84-1.11)$ & $1.00(0.81-1.17)$ & $1.00(0.91-1.09)$ \\
\hline Preoperative SMI $\left(\mathrm{cm}^{2} / \mathrm{m}^{2}\right)^{a}$ & $45.2(28.3-64.3)$ & $46.2(27.7-71.4)$ & $37.7(29.4-49.6)$ & $36.5(22.6-52.8)$ \\
\hline $\mathrm{HR}^{\mathrm{c}}$ & $0.98(0.95-1.01)$ & $0.95(0.90-1.01)$ & $0.91(0.75-1.08)$ & $0.99(0.93-1.04)$ \\
\hline Postoperative SMI $\left(\mathrm{cm}^{2} / \mathrm{m}^{2}\right)^{\mathrm{a}}$ & $43.3(27.2-63.5)$ & $45(23.7-69.0)$ & $37.0(29.0-46.9)$ & $35.3(21.8-50.9)$ \\
\hline$P^{b}$ & $0.007^{*}$ & 0.12 & 0.79 & 0.17 \\
\hline $\mathrm{HR}^{\mathrm{c}}$ & $0.95(0.92-0.98)$ & $1.02(0.94-1.09)$ & $1.08(0.97-1.17)$ & $0.95(0.90-0.99)$ \\
\hline
\end{tabular}

${ }^{\mathrm{a}}$, continuous variables are presented as median (range). ${ }^{\mathrm{b}}$, Cox proportional hazard analyses were performed as univariate analysis. ${ }^{\mathrm{c}}$, hazard ratios and $95 \%$ confidence intervals in parenthesis. Hazard ratios per one-unit increase were presented. ${ }^{d}$, the association of postoperative change of SMI and survival from postoperative 6 months was denied in multivariate analysis. See Table S1. *, statistically significant. BI, Brinkman index; N, number; HR, hazard ratio; BMI, body mass index; SMI, skeletal muscle index. 


\section{Changes in SMI associated with postoperative mortality in beavy-smoking males}

Table $S 4$ displays patient characteristics and the results of the univariate survival analyses in heavy-smoking males. Table 2 shows the results of the multivariate analyses, revealing that the 6-month depletion in SMI as a continuous variable was independently associated with poor prognosis.

Table 2 Multivariate analysis of factors associated with poor survival from 6 months after surgery in 391 males with Brinkman index $\geq 600$

\begin{tabular}{|c|c|c|}
\hline Variables & $P$ value ${ }^{a}$ & $\mathrm{HR}(95 \% \mathrm{Cl})$ \\
\hline SMI rate of change ${ }^{b}$ & $0.0027^{*}$ & $0.95(0.93-0.98)^{d}$ \\
\hline Preoperative $\mathrm{BMI}^{\mathrm{b}}$ & $0.0044^{*}$ & $0.91(0.85-0.97)^{d}$ \\
\hline Brinkman index ${ }^{b}$ & $0.0018^{*}$ & $1.0006(1.0002-1.0009)^{d}$ \\
\hline Preoperative $\mathrm{PaO}_{2}{ }^{\mathrm{b}}$ & $0.017^{*}$ & $0.97(0.95-0.99)^{d}$ \\
\hline Pathological stage $\geq \|^{c}{ }^{c}$ & $0.0074^{*}$ & $2.03(1.24-3.03)$ \\
\hline Pleural invasion ${ }^{c}$ & $0.037^{\star}$ & $1.52(1.03-2.27)$ \\
\hline Lymphovascular invasion $^{c}$ & $0.005^{\star}$ & $2.00(1.24-3.23)$ \\
\hline
\end{tabular}

a, Cox proportional hazards analysis. ${ }^{\mathrm{b}}$, continuous variable. ${ }^{\mathrm{c}}$, categorical variables. ${ }^{d}$, hazard ratio per one-unit increase. *, statistically significant. HR, hazard ratio; $\mathrm{Cl}$, confidence interval; $\mathrm{SMI}$, skeletal muscle mass index; $\mathrm{BMI}$, body mass index; $\mathrm{PaO}_{2}$, partial pressure of oxygen in arterial blood.

\section{Identifying the optimal SMI change cut-off value}

In our previous study (14), the optimal cut-off value of the 6-month SMI change in heavy smokers with $\mathrm{BI} \geq 600$ ( $\mathrm{N}=196)$ was $-10.2 \%$. Similarly, in this study, the ROC analysis for mortality indicated the optimal cut-off value for the 6-month change in SMI was $-10.0 \%$ [area under the curve (AUC): 0.56 Youden's index: 0.13]. Figure 2 shows the curves for overall survival in patients with and without a change in the SMI of $\leq-10 \%$. A change in $\mathrm{SMI} \leq-10 \%$ was strongly associated with poor prognosis in the multivariate analysis (Table 3).

\section{Factors associated with postoperative changes in SMI $\leq-10 \%$}

Table 4 illustrates the results of univariate analysis for the clinicopathological factors associated with postoperative changes of $\mathrm{SMI} \leq-10 \%$. The results of multivariate analysis are shown in Tables 5 and 6. Operation time (cut-off value of 200 minutes), forced expiratory volume in one second (FEV 1.0, cut-off value of $1,870 \mathrm{~mL}$ ) and past history of other cancers were significant risk factors for postoperative changes in the SMI.

\section{Discussion}

In a larger population than our previous study, the present

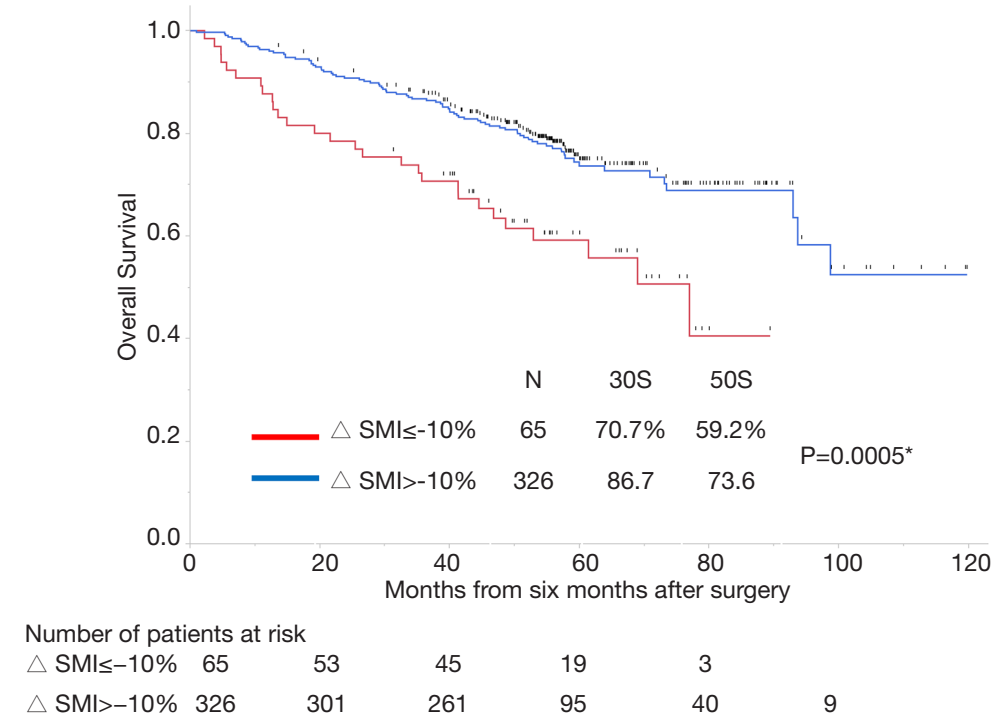

Figure 2 Overall survival curve of patients with or without a change of $\leq-10 \%$ in their postoperative skeletal muscle index. N, number; 3OS, 3-year overall survival; 5OS, 5-year overall survival; SMI, skeletal muscle index; $\triangle \mathrm{SMI}$, the SMI rate of change; P value, Log-rank test, *, statistically significant. 
Table 3 Multivariate analysis of the factors associated with poor survival from postoperative six months in 391 males with a history of heavy smoking using dichotomous variables converted by cut-off value

\begin{tabular}{lcc}
\hline Variables & $\mathrm{P}$ value & $\mathrm{HR}(95 \% \mathrm{Cl})$ \\
\hline SMI rate of change $\leq-10 \%^{\mathrm{b}}$ & $0.0018^{*}$ & $2.01(1.30-3.12)$ \\
Preoperative $\mathrm{BMI} \leq 20.3^{\mathrm{b}}$ & $0.0004^{*}$ & $2.11(1.40-3.18)$ \\
Brinkman index $\geq 1,230^{\mathrm{b}}$ & $<0.0001^{*}$ & $2.24(1.52-3.29)$ \\
Preoperative $\mathrm{PaO}_{2} \leq 86.8$ Torr $^{\mathrm{b}}$ & $0.0012^{*}$ & $2.12(1.34-3.36)$ \\
Pathological stage $\geq \mathrm{III}$ & $0.0044^{*}$ & $2.02(1.25-3.28)$ \\
Lymphovascular invasion & $0.0006^{*}$ & $2.29(1.43-3.68)$ \\
Pleural invasion & 0.12 & $1.38(0.92-2.05)$ \\
\hline
\end{tabular}

${ }^{a}$, Cox proportional hazards analysis. ${ }^{b}$, these cut-off values were determined using the maximum Youden's index value on the receiver operating characteristic $(\mathrm{ROC})$ curve for the mortality, which was the same way as the cut-off value of SMI rate of change was determined. *, statistically significant. HR, hazard ratio; $\mathrm{Cl}$, confidence interval; $\mathrm{SMI}$, skeletal muscle mass index; $\mathrm{BMI}$, body mass index; $\mathrm{PaO}_{2}$, partial pressure of oxygen in arterial blood.

study confirmed that the 6-month postoperative changes in SMI as a continuous variable predicted the prognosis from 6 months after complete lung cancer resection in heavy-smoking males, independent of tumor factors such as pathological stage and lymphovascular invasion. Furthermore, we identified the risk factors associated with postoperative changes of SMI $\leq-10 \%$.

These results support the necessity of preventing perioperative progression of sarcopenia after curative resection of lung cancer, especially in heavy smokers. It is reasonable to investigate risk factors for postoperative sarcopenia only in heavy smokers (heavy-smoking males in our study) as postoperative sarcopenia was demonstrated to be associated with their prognosis. Sarcopenia is also seen in COPD patients, which is mainly caused by increased energy expenditure due to impaired respiration, which is also defined as pulmonary cachexia (23-25). The progression of sarcopenia after complete resection of lung cancer could be further facilitated as respiratory function is impaired by lung resection. The results in Table 1 showed there were no significant differences in the reduction of SMI values across the four groups stratified by sex and smoking history. It is possible that the decline in the SMI in the 6 months after surgery could be the trigger for progression of pulmonary- or cancer-related sarcopenia, or both, in patients with histories of heavy smoking. Many patients died because of cancer progression (lung cancer or other cancers) and respiratory diseases (e.g., pneumonia and interstitial pneumonitis) (Table $S 5$ ), which could have been affected by sarcopenia. If recurrence of the primary cancer or another cancer occurs, the tendency toward sarcopenia may be accelerated. Several reports involving different chemotherapy regimens have described a decrease in SMA ranging between 5-8\% $(26,27)$ and sarcopenia were associated with treatment toxicity (28-30). These findings suggest that administering treatments for recurrent or other de novo cancers, the prevention of sarcopenia may be important.

It was expected that the low preoperative BMI would be a risk factor for poor prognosis from 6 months after lung cancer resection, independently of the change of SMI. As indicated by the currently proposed definitions and severity grading systems for both generic and cancer cachexia $(1,2)$, an absolute value of a surrogate marker for cachexia should be considered alongside a decrease in value. In our former study (14), preoperative BMI was not identified as a risk factor. In the present study, the influence of the preoperative BMI was clarified mainly because we focused on large population of heavy-smoking males. Table 1 shows that the preoperative BMI value had a stronger association with prognosis than the preoperative SMI, although the preoperative BMI and SMI had a relatively strong linear association (correlation coefficient $=0.64$ ). Through progression of emaciation, adipose tissue is catabolized first and muscle tissue is consumed when adipose tissue is depleted. Therefore, the preoperative BMI value including the volume of adipose tissue may screen for patients at risk for postoperative sarcopenia and prognosis more comprehensively than preoperative SMI values. Postoperative SMI was supposed to be eliminated because of the change of SMI in our multivariate analysis. Unfortunately, we could not obtain postoperative BMI vales. In western countries, where the proportion of overweight and obese patients is increasing, it has been reported that the SMI was superior to BMI as a prognostic factor (5). If we restrict our analysis to heavy smokers, both the absolute $\mathrm{BMI}$ value and the postoperative changes in the BMI, and not in the SMI, might be more strongly associated with postoperative prognosis. However, the preoperative BMI is a fixed value before surgery, which remains invariant perioperatively.

Tables 5 and 6 show preoperative history of other cancers, low preoperative FEV1.0 and prolonged operating 
Table 4 Univariate analyses of SMI rate of change $\leq-10 \%$ in 391 males with Brinkman index $\geq 600$

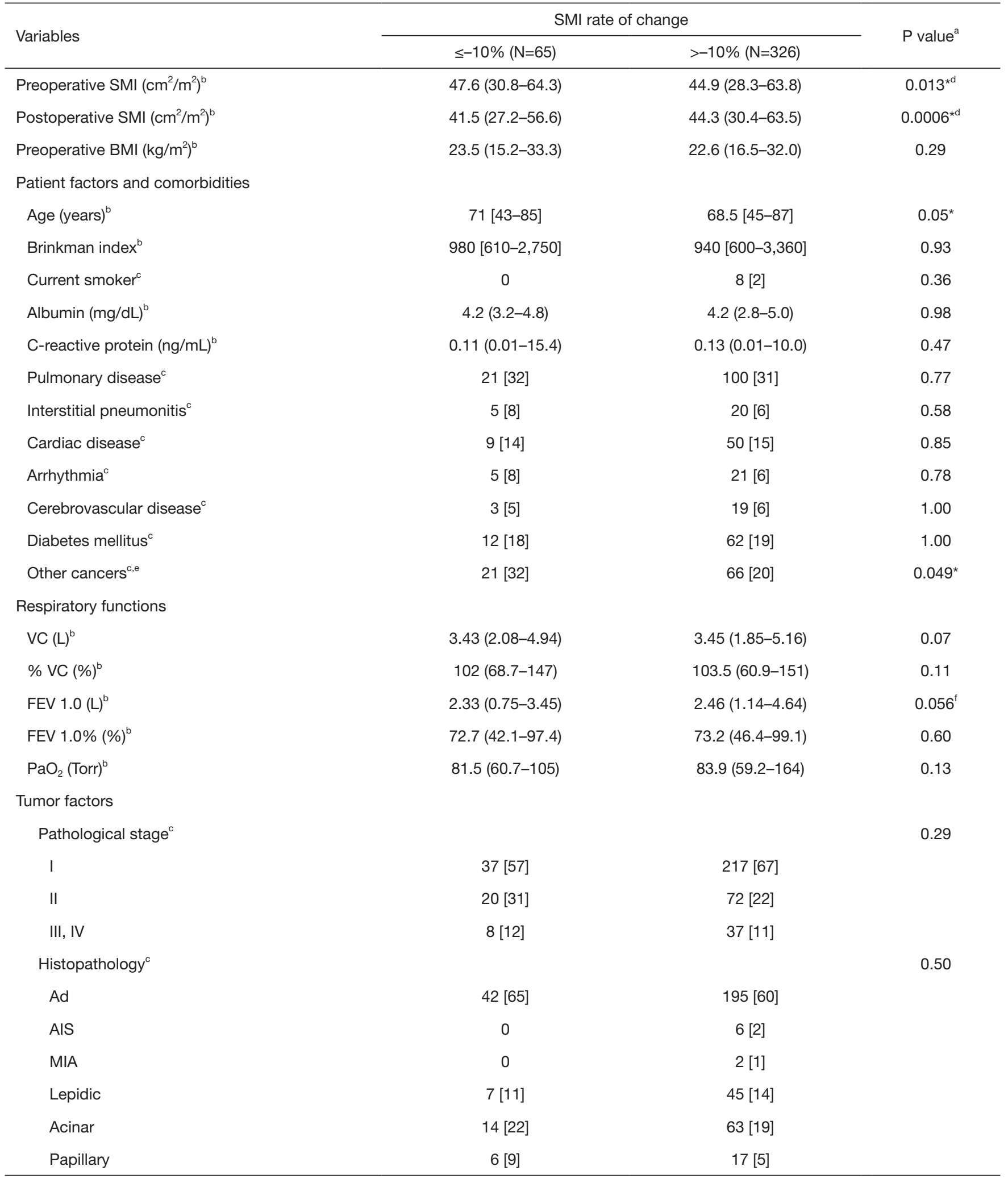

Table 4 (Continued) 
Table 4 (Continued)

\begin{tabular}{|c|c|c|c|}
\hline Variables & \multicolumn{2}{|c|}{ SMI rate of change } & $P$ value ${ }^{a}$ \\
\hline Micropapillary & $1[2]$ & $4[1]$ & \\
\hline Solid & $9[14]$ & $42[13]$ & \\
\hline Mucinous & $3[4]$ & 6 [2] & \\
\hline $\mathrm{Sq}$ & $17[26]$ & 84 [26] & \\
\hline Others & $6[9]$ & $47[14]$ & \\
\hline Pleural invasion ${ }^{c}$ & $27[42]$ & $110[34]$ & 0.25 \\
\hline Lymphovascular invasion ${ }^{c}$ & $39[60]$ & $170[52]$ & 0.28 \\
\hline \multicolumn{4}{|l|}{ Operative factors } \\
\hline Resected lobe ${ }^{c}$ & & & 0.92 \\
\hline RUL & $25[38]$ & $117[36]$ & \\
\hline RML & $3[5]$ & $16[5]$ & \\
\hline RLL & $12[18]$ & $52[16]$ & \\
\hline LUL & $18[28]$ & $93[28]$ & \\
\hline LLL & $7[11]$ & $48[15]$ & \\
\hline Lymph node dissection $^{c}$ & & & 0.22 \\
\hline Bleeding $(\mathrm{mL})^{\mathrm{b}}$ & 40 [little-2,105] & 30 [little-1,210] & $0.001^{*}$ \\
\hline Preoperative therapy ${ }^{c}$ & $5[8]$ & $14[4]$ & 0.33 \\
\hline Postoperative therapy ${ }^{c}$ & $23[35]$ & $103[32]$ & $0.05^{\star}$ \\
\hline
\end{tabular}

${ }^{a}$, Wilcoxon rank sum test for continuous variables and Fisher's exact test or $\chi^{2}$ test (for more than $2 \times 2$ test) for categorical variables. ${ }^{b}$, continuous variables are presented as median (range). ${ }^{c}$, categorical variables are presented as number [percentage]. ${ }^{\mathrm{d}}$, preoperative and postoperative SMI were excluded from multivariate analysis because there were strong linear associations between SMI rate of change and pre- and postoperative SMI. ${ }^{e}$, history of other cancers that were cured or were under control at the time of operation for lung cancer. ${ }^{f}$, these variables were included in multivariate analysis though $\mathrm{P}$ value did not reach $<0.05$ in these variables. ${ }^{9}$, non-systemic sampling of lymph nodes. ' , systemic dissection to the extent of hilar lymph nodes ', systemic dissection to the extent of upper or/and lower mediastinal lymph nodes ${ }^{j}$, short-term postoperative complications (all types and grades of short-term postoperative complications in the patients' medical records). *, statistically significant. SMI, skeletal muscle index; N, number; BMI, body mass index; VC, vital capacity; \%VC, vital capacity percentage; FEV 1.0, forced expiratory volume in one second; FEV 1.0\%, forced expiratory volume in one second percentage; $\mathrm{PaO}_{2}$, partial pressure of oxygen in arterial blood; Ad, adenocarcinoma; AIS, adenocarcinoma in situ; MIA, minimally invasive adenocarcinoma; Sq, squamous cell carcinoma; CEA, carcinoembryonic antigen; LUL, left upper lobe; LLL, left lower lobe; RUL, right upper lobe; RML, right middle lobe; RLL, right lower lobe. 
time were risk factors for postoperative progression of sarcopenia. There has been some speculation as to whether preoperative sarcopenia indicates the presence of microresidual lesions or micro-metastases (31); however, our results suggest that cancer recurrence after postoperative 6 months and tumor factors such as pathological stage and lymphovascular invasion were not related to the decrease in the SMI during the 6-month post-operative follow-up.

Table S6 displays the cancers affected before the lung cancer resection. These include cancers of the upper gastro-intestinal tract and urinary system, the occurrences of which are more common in heavy smokers. All forms of cancer other than colorectal cancer tended to have a higher proportion of postoperative change in SMI of $\leq-10 \%$; however, the differences were not statistically significant. Gastric cancer was observed most commonly and tended to be associated with the postoperative change of SMI of $\leq-10 \%$ $(\mathrm{P}=0.08$, Fisher's exact test). Patients with gastric cancer had a $\mathrm{BMI} \leq 20.3$ before the lung cancer surgery significantly more often. These patients likely had nutritional problems mainly due to gastric resection. Reports on the association of sarcopenia defined by SMI with mortality after curative resection of gastric cancer have recently been published (9). Heavy smokers with a history of gastric cancer should be regarded as high-risk for progressive sarcopenia both before and after the lung cancer surgery, which is associated with long-term prognosis. This may not be frequently encountered in Europe and America, as gastric cancers are more common in Eastern Asia, including in Japan.

Low preoperative FEV1.0 was a risk factor for postoperative sarcopenia, although we analyzed many other variables in the respiratory function tests, including predicted postoperative values for the resected lobe and the COPD grade based on the of Global Initiative for Obstructive Lung Disease (GOLD) criteria. Preoperative factors of respiratory test outcomes were not related to longterm mortality; Takamori et al. reported similar results (18). There have been reports regarding the association between COPD and low respiratory function with prognosis following a lung cancer diagnosis $(25,32,33)$. However, patient backgrounds and the variables selected for analyses and outcomes differed across reports. In our analysis, we confined the study objectives to heavy-smoking males and excluded early death, recurrence, and severe complications. Moreover, we investigated the relationship between perioperative sarcopenia and the long-term prognosis from 6 months after complete resection of lung cancer. Our results suggest that patients with preoperative low FEV1.0 have a higher risk for postoperative sarcopenia leading to poor prognosis.

We found that longer operating time was a risk factor for postoperative sarcopenia. As thoracic surgeons, we would like to contribute to the prevention of postoperative progression of sarcopenia. Therefore, we should pay particular attention to the association of postoperative sarcopenia with factors associated with surgical procedures. There were no associations with other operative factors, including postoperative complications such as prolonged air leakage, associated with postoperative sarcopenia. Table $S 7$ reveals the relationship between additional procedures leading to prolonged operating times and postoperative sarcopenia. Additional procedures tended to prolong the operating time; however, these did not result in an increased frequency of postoperative sarcopenia. To our knowledge, there have been no reports that prolonged operating or anesthetic time can lead to the depletion of respiratory function or muscle mass following lung cancer surgery. Our cut-off value of two hundred minutes for operative time in our study may not be clinically significant regarding postoperative sarcopenia. The operation time affecting postoperative respiratory function and sarcopenia may be longer. We have often experienced patients with adhesions between visceral and parietal pleura leading to prolonged operation time due to dissection of the adhesion and control the complications like air leakage and bleeding induced by the dissection. Many of these patients had chronic intrathoracic inflammation due to COPD and other respiratory diseases. Therefore, they probably had poor prognosis postoperatively. We must consider such confounding factors. Further research examining the relationship between operation time and postoperative sarcopenia is needed.

Based on our results, the measures against sarcopenia in heavy smokers undergoing the lobe resection for lung cancer would involve shortening of the operating time for highrisk patients with a past history of other cancers, especially gastric cancer, or low FEV1.0 or both. The indication for limited surgery for heavy smokers might include these factors and a low BMI. However, among the risk factors for postoperative sarcopenia and mortality examined in our study, there were many factors that remained fixed preoperatively and only a few factors that could be improved perioperatively. Therefore, there is a need for clinical trials to be performed to assess the impact of perioperative antisarcopenia treatments to improve long-term prognosis. As the postoperative reduction of SMI as a continuous variable 
Table 5 Multivariate analyses of SMI rate of change $\leq-10 \%$ in 391 males with Brinkman index $\geq 600$

\begin{tabular}{|c|c|c|}
\hline Variables & $P$ value ${ }^{a}$ & OR $(95 \% \mathrm{Cl})$ \\
\hline Past histories of other cancers ${ }^{b}$ & $0.044^{*}$ & $1.89(1.03-3.47)$ \\
\hline FEV $1.0^{\circ}$ & $0.0044^{\star}$ & $0.56(0.33-0.96)^{d}$ \\
\hline Operation time ${ }^{c}$ & $0.0018^{\star}$ & $1.006(1.002-1.010)^{d}$ \\
\hline Postoperative complication $^{b}$ & 0.15 & $1.58(0.86-2.92)$ \\
\hline Postoperative treatment $^{b}$ & 0.13 & $1.59(0.88-2.89)$ \\
\hline
\end{tabular}

${ }^{a}$, logistic regression analysis. ${ }^{b}$, categorical variable. ${ }^{c}$, continuous variables. ${ }^{d}$, odds ratio per one-unit increase. *, statistically significant. $\mathrm{OR}$, odds ratio; $\mathrm{Cl}$, confidence interval; SMI, skeletal muscle index.

Table 6 Multivariate analyses of SMI rate of change $\leq-10 \%$ in 391 males with Brinkman index $\geq 600$ using dichotomous variables converted by cut-off value

\begin{tabular}{llc}
\hline Variables & $\mathrm{P}$ value & $\mathrm{OR}(95 \% \mathrm{Cl})$ \\
\hline Past histories of other cancers & $0.047^{*}$ & $1.86(1.01-3.43)$ \\
FEV $1.0 \leq 1,870 \mathrm{~mL}$ & $0.0039^{\star}$ & $2.87(1.44-5.74)$ \\
Operation time $\leq 200$ minutes & $0.020^{*}$ & $1.98(1.12-3.49)$ \\
Postoperative complication & 0.09 & $1.71(0.93-3.13)$ \\
Postoperative treatment & 0.14 & $1.58(0.87-2.86)$ \\
\hline
\end{tabular}

${ }^{a}$, logistic regression analysis. *, statistically significant. OR, odds ratio; $\mathrm{Cl}$, confidence interval; $\mathrm{SMI}$, skeletal muscle index.

was a risk factor for long-term prognosis in this study, measures to maintain muscle mass for all heavy smokers, especially in those with a low preoperative BMI, could be considered in order to prolong survival. As described in a previous study (14), current treatments for sarcopenia do not improve long-term prognosis in these patients, despite trials that have evaluated several nutritional therapies, rehabilitative techniques, and pharmacological methods (6,15-17). The reason for these failures may be that patients with advanced cancer might have advanced sarcopenia, that is refractory to treatment. Many of our patients were not sarcopenic or were in the early phases when clinical symptoms were absent [i.e., presarcopenia defined by European Working Group on Sarcopenia in Older People (3)]; moreover, these patients were cancer-free after the complete resection, albeit temporarily. In future studies, we would like to assess whether treatment of muscle loss for such patients could improve sarcopenia and long-term prognosis. There have been few trials investigating the association of postoperative rehabilitation and nutritional support with long-term prognosis after the resection of lung cancer. We found only one observational study with small number of patients investigating the association (34). Hence, we need to plan well-designed clinical trials including physical exercise and nutritional support. The trial should incorporate requirements to cease smoking. Unfortunately, we could not obtain and compare information regarding perioperative nutritional support and exercise training, which could be important factors to ameliorate muscle loss. There were some patients who maintained SMI despite risk factors for postoperative sarcopenia. It could be worth researching postoperative lifestyles of such patients to obtain clues regarding effective anti-sarcopenia therapies.

This study has several limitations that were similar to those of our previous study (14). First, the study might be biased for sarcopenia because patients with recurrence, death, and severe postoperative complications during the 6-month postoperative period were excluded. However, risk factors and countermeasures for sarcopenia for such patients should be considered separately. Second, variables indicating changes during the postoperative 6-month period other than SMI were limited. Third, this study was performed with a retrospective single-center design with small number of patients, which highlights the importance of prospective data accumulation at multiple centers. Fourth, we only considered Japanese patients. Our findings may not be generalizable to non-Japanese patients. Fifth, this study did not include those patients who underwent complete thoracoscopic surgery. The effects of less invasive surgery on postoperative sarcopenia would be an interesting issue for further investigation.

In conclusion, among patients who underwent complete lung cancer resection, a decrease in SMI during the 6-month postoperative follow-up period significantly predicted poor long-term prognosis in heavy smokers. Moreover, we identified risk factors for postoperative progression of sarcopenia. This generated clues regarding countermeasures. Nevertheless, thoracic surgeons should further investigate approaches to prevent perioperative sarcopenia in future studies, including clinical trials.

\section{Acknowledgments}

The authors would like to thank Tomofumi Hayashi, Ryoko Kowata, Sawako Aoyagi, Hiroki Nakamura, Yuki Ootsuki 
and Mitsuhiro Akama, staffs of Department of Radiological Technologists (Diagnosis), Kanagawa Cancer Center, Yokohama, Japan, for anonymizing and providing the CT scans.

Funding: None.

\section{Footnote}

Conflicts of Interest: The authors have no conflicts of interest to declare.

Ethical Statement: The authors are accountable for all aspects of the work in ensuring that questions related to the accuracy or integrity of any part of the work are appropriately investigated and resolved. The study's protocol complied with the Declaration of Helsinki and was approved by the institutional review board of Kanagawa Cancer Center (ID 2018-103). The need for patient consent was waived because all data in this study were completely anonymized.

Open Access Statement: This is an Open Access article distributed in accordance with the Creative Commons Attribution-NonCommercial-NoDerivs 4.0 International License (CC BY-NC-ND 4.0), which permits the noncommercial replication and distribution of the article with the strict proviso that no changes or edits are made and the original work is properly cited (including links to both the formal publication through the relevant DOI and the license). See: https://creativecommons.org/licenses/by-nc-nd/4.0/.

\section{References}

1. Evans WJ, Morley JE, Argiles J, et al. Cachexia: a new definition. Clin Nutr 2008;27:793-9.

2. Fearon K, Strasser F, Anker SD, et al. Definition and classification of cancer cachexia: an international consensus. Lancet Oncol 2011;12:489-95.

3. Cruz-Jentoft AJ, Baeyens JP, Bauer JM, et al. Sarcopenia: European consensus on definition and diagnosis: Report of the European Working Group on Sarcopenia in Older People. Age Ageing 2010;39:412-23.

4. Mourtzakis M, Prado CM, Lieffers JR, et al. A practical and precise approach to quantification of body composition in cancer patients using computed tomography images acquired during routine care. Appl Physiol Nutr Metab 2008;33:997-1006.

5. Martin L, Birdsell L, Macdonald N, et al. Cancer cachexia in the age of obesity: skeletal muscle depletion is a powerful prognostic factor, independent of body mass index. J Clin Oncol 2013;31:1539-47.

6. Jafri SH, Previgliano C, Khandelwal K, et al. Cachexia index in advanced non-small-cell lung cancer patients. Clin Med Insights Oncol 2015;9:87-93.

7. Choi Y, Oh DY, Kim TY, et al. Skeletal muscle depletion predicts the prognosis of patients with advanced pancreatic cancer undergoing palliative chemotherapy, independent of body mass index. PLoS One 2015;10:e0139749.

8. Zheng ZF, Lu J, Zheng CH, et al. A novel prognostic scoring system based on preoperative sarcopenia predicts the long-term outcome for patients after $\mathrm{r} 0$ resection for gastric cancer: experiences of a high-volume center. Ann Surg Oncol 2017;24:1795-803.

9. Mayanagi S, Tsubosa Y, Omae K, et al. Negative impact of skeletal muscle wasting after neoadjuvant chemotherapy followed by surgery on survival for patients with thoracic esophageal cancer. Ann Surg Oncol 2017;24:3741-7.

10. Suzuki Y, Okamoto T, Fujishita T, et al. Clinical implications of sarcopenia in patients undergoing complete resection for early non-small cell lung cancer. Lung Cancer 2016;101:92-7.

11. Deng HY, Hou L, Zha P, et al. Sarcopenia is an independent unfavorable prognostic factor of non-small cell lung cancer after surgical resection: A comprehensive systematic review and meta-analysis. Eur J Surg Oncol 2019;45:728-35.

12. Nakamura R, Inage $Y$, Tobita R, et al. Sarcopenia in resected NSCLC: Effect on postoperative outcomes. J Thorac Oncol 2018;13:895-903.

13. Nishimura JM, Ansari AZ, D'Souza DM, et al. Computed tomography-assessed skeletal muscle mass as a predictor of outcomes in lung cancer surgery. Ann Thorac Surg 2019. doi: 10.1016/j.athoracsur.2019.04.090.

14. Nagata M, Ito H, Yokose T, et al. Effect of progressive sarcopenia during postoperative 6 months on long-term prognosis of completely resected lung cancer. J Thorac Dis 2019;11:3411-20.

15. Strasser F. Appraisal of current and experimental approaches to the treatment of cachexia. Curr Opin Support Palliat Care 2007;1:312-6.

16. Fearon K, Argiles JM, Baracos VE, et al. Request for regulatory guidance for cancer cachexia intervention trials. J Cachexia Sarcopenia Muscle 2015;6:272-4.

17. Mondello P, Mian M, Aloisi C, et al. Cancer cachexia syndrome: pathogenesis, diagnosis, and new therapeutic options. Nutr Cancer 2015;67:12-26. 
18. Takamori S, Toyokawa G, Okamoto T, et al. Clinical impact and risk factors for skeletal muscle loss after complete resection of early non-small cell lung cancer. Ann Surg Oncol 2018;25:1229-36.

19. Rusch VW, Asamura H, Watanabe H, et al. The IASLC lung cancer staging project: a proposal for a new international lymph node map in the forthcoming seventh edition of the TNM classification for lung cancer. J Thorac Oncol 2009;4:568-77.

20. Baracos VE, Reiman T, Mourtzakis M, et al. Body composition in patients with non-small cell lung cancer: a contemporary view of cancer cachexia with the use of computed tomography image analysis. Am J Clin Nutr 2010;91:1133S-7S.

21. Prado CM, Lieffers JR, McCargar LJ, et al. Prevalence and clinical implications of sarcopenic obesity in patients with solid tumours of the respiratory and gastrointestinal tracts: a population-based study. Lancet Oncol 2008;9:629-35.

22. Perthen JE, Ali T, McCulloch D, Navidi M, et al. Intra- and interobserver variability in skeletal muscle measurements using computed tomography images. Eur J Radiol 2018;109:142-6.

23. Landbo C, Prescott E, Lange P, et al. Prognostic value of nutritional status in chronic obstructive pulmonary disease. Am J Respir Crit Care Med 1999;160:1856-61.

24. Schols AM. Pulmonary cachexia. Int J Cardiol 2002;85:101-10.

25. Lee SJ, Lee J, Park YS, et al. Impact of chronic obstructive pulmonary disease on the mortality of patients with nonsmall-cell lung cancer. J Thorac Oncol 2014;9:812-7.

26. Antoun S, Birdsell L, Sawyer MB, et al. Association of skeletal muscle wasting with treatment with sorafenib in

Cite this article as: Nagata M, Ito H, Yoshida T, Tokushige A, Ueda S, Yokose T, Nakayama H. Risk factors for progressive sarcopenia 6 months after complete resection of lung cancer: what can thoracic surgeons do against sarcopenia? J Thorac Dis 2020;12(3):307-318. doi: 10.21037/jtd.2020.01.44 patients with advanced renal cell carcinoma: results from a placebo-controlled study. J Clin Oncol 2010;28:1054-60.

27. Awad S, Tan BH, Cui H, et al. Marked changes in body composition following neoadjuvant chemotherapy for oesophagogastric cancer. Clin Nutr 2012;31:74-7.

28. Sjøblom B, Gronberg BH, Benth JS, et al. Low muscle mass is associated with chemotherapy-induced haematological toxicity in advanced non-small cell lung cancer. Lung Cancer 2015;90:85-91.

29. Prado CM, Baracos VE, McCargar LJ, et al. Sarcopenia as a determinant of chemotherapy toxicity and time to tumor progression in metastatic breast cancer patients receiving capecitabine treatment. Clin Cancer Res 2009;15:2920-6.

30. Ali R, Baracos VE, Sawyer MB, et al. Lean body mass as an independent determinant of dose-limiting toxicity and neuropathy in patients with colon cancer treated with FOLFOX regimens. Cancer Med 2016;5:607-16.

31. Icard P, Iannelli A, Lincet H, et al. Sarcopenia in resected non-small cell lung cancer: let's move to patient-directed strategies. J Thorac Dis 2018;10:S3138-42.

32. Sekine Y, Yamada Y, Chiyo M, et al. Association of chronic obstructive pulmonary disease and tumor recurrence in patients with stage IA lung cancer after complete resection. Ann Thorac Surg 2007;84:946-50.

33. Ferguson MK, Watson S, Johnson E, et al. Predicted postoperative lung function is associated with all-cause long-term mortality after major lung resection for cancer. Eur J Cardiothorac Surg 2014;45:660-4.

34. Marhic A, Dakhil B, Plantefeve G, et al. Long-term survival following lung surgery for cancer in high-risk patients after perioperative pulmonary rehabilitation. Interact Cardiovasc Thorac Surg 2019;28:235-9. 
Supplementary

Table S1 Multivariate analysis of factors associated with poor survival from 6 months after surgery in 445 females with Brinkman index $<600$

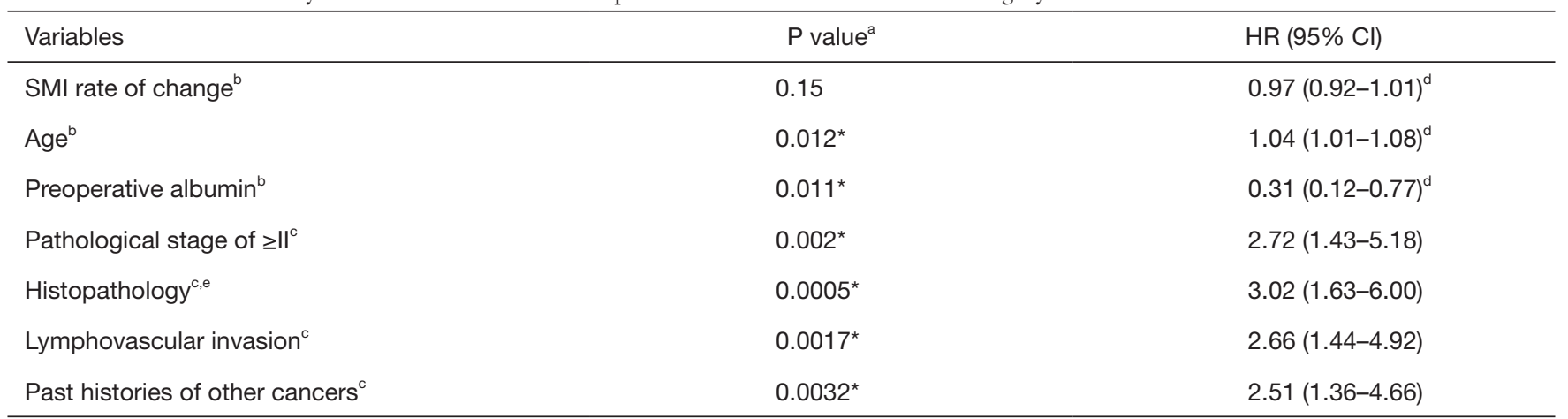

${ }^{a}$, Cox proportional hazards analysis. ${ }^{b}$, continuous variable. ${ }^{c}$, categorical variables. ${ }^{d}$, hazard ratio per one-unit increase. ${ }^{e}$, adenocarcinoma in situ, minimal invasive adenocarcinoma and lepidic pattern predominant invasive adenocarcinoma had significantly better prognosis than the others. *, statistically significant. HR, hazard ratio; $\mathrm{Cl}$, confidence interval; SMI, skeletal muscle index. 
Table S2 Clinicopathological characteristics in 225 males with Brinkman index $<600$ and 34 females with Brinkman index $\geq 600$

\begin{tabular}{|c|c|c|}
\hline Variables & Males with $\mathrm{Bl}<600(\mathrm{~N}=225)$ & Females with $\mathrm{Bl} \geq 600(\mathrm{~N}=34)$ \\
\hline SMI rate of change $(\%)^{a}$ & $-3.31(-19.6$ to 14.3$)$ & $-5.00(-12.6$ to 17.9$)$ \\
\hline Preoperative SMI $\left(\mathrm{cm}^{2} / \mathrm{m}^{2}\right)^{a}$ & $46.2(27.7-71.4)$ & $37.7(29.4-49.6)$ \\
\hline Postoperative SMI $\left(\mathrm{cm}^{2} / \mathrm{m}^{2}\right)^{\mathrm{a}}$ & $45(23.7-69.0)$ & $37.0(29.0-46.9)$ \\
\hline Preoperative BMI $\left(\mathrm{kg} / \mathrm{m}^{2}\right)^{\mathrm{a}}$ & $22.8(15.5-33.9)$ & $20.9(16.9-34.5)$ \\
\hline \multicolumn{3}{|c|}{ Patient factors and comorbidities } \\
\hline Age (years) $)^{a}$ & 70 [20-88] & 67.5 [54-82] \\
\hline \multicolumn{3}{|l|}{ Brinkman index ${ }^{\mathrm{b}}$} \\
\hline 0 & 75 [33] & \\
\hline $1-599$ & $150[67]$ & \\
\hline Brinkman index ${ }^{a}$ & & $850[600-1,720]$ \\
\hline Current smoker ${ }^{\mathrm{b}}$ & 4 [2] & $1[3]$ \\
\hline Albumin $(\mathrm{mg} / \mathrm{dL})^{\mathrm{a}}$ & $4.3(3.2-5.0)$ & $4.2(3.3-4.7)$ \\
\hline C-reactive protein $(\mathrm{ng} / \mathrm{mL})^{\mathrm{a}}$ & $0.07(0.01-9.96)$ & $0.1(0.01-1.62)$ \\
\hline Pulmonary disease $^{\mathrm{b}}$ & $30[13]$ & 8 [24] \\
\hline Interstitial pneumonitis ${ }^{\mathrm{b}}$ & $6[3]$ & $2[6]$ \\
\hline Cardiac disease $^{\mathrm{b}}$ & $27[12]$ & $4[12]$ \\
\hline Arrhythmia $^{\mathrm{b}}$ & $15[7]$ & $2[6]$ \\
\hline Cerebrovascular disease $^{b}$ & 12 [5] & $2[6]$ \\
\hline Diabetes mellitus $^{\mathrm{b}}$ & $28[12]$ & $8[24]$ \\
\hline Other cancers ${ }^{\mathrm{b}, \mathrm{c}}$ & $38[17]$ & 9 [26] \\
\hline \multicolumn{3}{|l|}{ Respiratory functions } \\
\hline $\operatorname{VC}\left(L^{\mathrm{a}}\right.$ & $3.48(1.92-5.58)$ & $2.33(1.62-3.11)$ \\
\hline$\%$ VC (\%) $)^{a}$ & $106(64.9-155)$ & $104.5(79.8-133)$ \\
\hline FEV $1.0(L)^{a}$ & $2.71(1.42-4.48)$ & $1.67(1.16-2.28)$ \\
\hline FEV $1.0 \%(\%)^{\mathrm{a}}$ & $77.8(53.8-90)$ & $73.3(55.9-84.9)$ \\
\hline $\mathrm{PaO}_{2}(\text { Torr })^{\mathrm{a}}$ & $86.7(68.2-110)$ & $62.7(66.4-124)$ \\
\hline \multicolumn{3}{|l|}{ Tumor factors } \\
\hline \multicolumn{3}{|l|}{ Pathological stage ${ }^{b}$} \\
\hline । & 169 [75] & $25[73]$ \\
\hline ॥ & $35[16]$ & $6[18]$ \\
\hline III, IV & $21[9]$ & $3[9]$ \\
\hline \multicolumn{3}{|l|}{ Histopathology ${ }^{\mathrm{b}}$} \\
\hline $\mathrm{Ad}$ & 199 [88] & $15[44]$ \\
\hline AIS & $10[4]$ & 0 \\
\hline MIA & $7[3]$ & $1[3]$ \\
\hline Lepidic & $74[33]$ & $1[3]$ \\
\hline Acinar & $52[24]$ & $4[12]$ \\
\hline Papillary & $25[11]$ & $1[3]$ \\
\hline Micropapillary & 4 [2] & 0 \\
\hline Solid & $14[6]$ & 7 [20] \\
\hline Mucinous & $10[4]$ & 0 \\
\hline Others & $3[1]$ & $1[3]$ \\
\hline $\mathrm{Sq}$ & $13[6]$ & $15[44]$ \\
\hline Others & $13[6]$ & $4[12]$ \\
\hline Pleural invasion ${ }^{\mathrm{b}}$ & $40[18]$ & $11[32]$ \\
\hline Lymphovascular invasion ${ }^{\mathrm{b}}$ & $74[33]$ & $23[68]$ \\
\hline CEA of $>5.0 \mathrm{ng} / \mathrm{mL}^{\mathrm{b}}$ & $37[16]$ & $12[35]$ \\
\hline \multicolumn{3}{|l|}{ Operative factors } \\
\hline \multicolumn{3}{|l|}{ Resected lobe ${ }^{b}$} \\
\hline RUL & $79[35]$ & $14[41]$ \\
\hline RML & $18[8]$ & $2[6]$ \\
\hline RLL & $49[22]$ & 8 [23] \\
\hline LUL & $47[21]$ & $6[18]$ \\
\hline LLL & $32[14]$ & $4[12]$ \\
\hline \multicolumn{3}{|l|}{ Lymph node dissection ${ }^{\mathrm{b}}$} \\
\hline Sampling $^{d}$ & $8[4]$ & 0 \\
\hline Hilar & $47[21]$ & $6[18]$ \\
\hline Mediastinal $^{\dagger}$ & 170 [75] & $28[82]$ \\
\hline Complications $^{\mathrm{c}, q}$ & $40[18]$ & $4[12]$ \\
\hline Operation time $(\mathrm{min})^{\mathrm{a}}$ & 163 [62-383] & $139.5[61-284]$ \\
\hline Bleeding $(\mathrm{mL})^{\mathrm{a}}$ & 30 [little-580] & 20 [little-400] \\
\hline Preoperative therapy ${ }^{b}$ & 4 [2] & $3[9]$ \\
\hline Postoperative therapy & $61[27]$ & $10[29]$ \\
\hline
\end{tabular}

${ }^{\text {a }}$, continuous variables are presented as median (range). ${ }^{b}$, categorical variables are presented as number [percentage] ${ }^{\circ}$, history of other cancers that were cured or were under control at the time of operation for lung cancer. ${ }^{d}$, non-systemic sampling of lymph nodes. ', systemic dissection to the extent of hilar lymph nodes ${ }^{f}$, systemic dissection to the extent of upper or/and lower mediastinal lymph nodes. ${ }^{9}$, short-term postoperative complications (all types and grades of short-term postoperative complications in the medical records). SMI, skeletal muscle index; BMI, body mass index; VC, vital capacity; \%VC, vital capacity percentage; FEV 1.0, forced expiratory volume in one second; FEV $1.0 \%$, forced expiratory volume in one second percentage; $\mathrm{PaO}_{2}$, partial pressure of oxygen in arterial blood; Ad, adenocarcinoma; AIS, adenocarcinoma in situ; MIA, minimally invasive adenocarcinoma; Sq, squamous cell carcinoma; CEA, carcinoembryonic antigen; LUL, left upper lobe; LLL, left lower lobe; RUL, right upper lobe; RML, right middle lobe; RLL, right lower lobe. 
Table S3 Clinicopathological characteristics and univariate analyses of mortality from postoperative six months in 445 females with Brinkman index $<600$

\begin{tabular}{|c|c|c|}
\hline Variables & Females with $\mathrm{BI}<600(\mathrm{~N}=445)$ & $P$ value \\
\hline SMI rate of change $(\%)^{b}$ & $-3.21(-18.6$ to 14.7$)$ & $0.031^{*}$ \\
\hline Preoperative SMI $\left(\mathrm{cm}^{2} / \mathrm{m}^{2}\right)^{b}$ & $36.5(22.6-52.8)$ & 0.65 \\
\hline Postoperative SMI $\left(\mathrm{cm}^{2} / \mathrm{m}^{2}\right)^{b}$ & $35.3(21.8-50.9)$ & 0.17 \\
\hline Preoperative BMI $\left(\mathrm{kg} / \mathrm{m}^{2}\right)^{\mathrm{b}}$ & $22.8(15.5-33.9)$ & 0.99 \\
\hline \multicolumn{3}{|c|}{ Patient factors and comorbidities } \\
\hline Age $(\text { years })^{b}$ & 68 [36-88] & $0.002^{*}$ \\
\hline Brinkman index ${ }^{c}$ & & 0.63 \\
\hline 0 & 364 [82] & \\
\hline $1-599$ & $81[18]$ & \\
\hline Current smoker $^{\mathrm{C}}$ & $2[<1]$ & 0.47 \\
\hline Albumin $(\mathrm{mg} / \mathrm{dL})^{\mathrm{b}}$ & $4.3(3.3-5.0)$ & $0.002^{*}$ \\
\hline C-reactive protein $(\mathrm{ng} / \mathrm{mL})^{\mathrm{b}}$ & $0.05(0.01-4.31)$ & 0.35 \\
\hline Pulmonary disease $^{\circ}$ & 53 [12] & 0.88 \\
\hline Interstitial pneumonitis $^{\mathrm{c}}$ & $5[1]$ & 0.58 \\
\hline Cardiac disease $^{c}$ & $26[6]$ & 0.86 \\
\hline Arrhythmia $^{c}$ & $24[5]$ & 0.71 \\
\hline Cerebrovascular disease $^{c}$ & $18[4]$ & 0.46 \\
\hline Diabetes mellitus $^{c}$ & $28[6]$ & 0.29 \\
\hline Other cancers ${ }^{c, d}$ & $71[16]$ & $0.029^{*}$ \\
\hline \multicolumn{3}{|l|}{ Respiratory functions } \\
\hline VC (L) $)^{b}$ & $2.47(1.34-3.75)$ & $0.007^{*}$ \\
\hline$\%$ VC $(\%)^{b}$ & $108(57.9-153)$ & 0.11 \\
\hline FEV $1.0(\mathrm{~L})^{\mathrm{b}}$ & $1.9(0.87-3.16)$ & $0.008^{*}$ \\
\hline FEV $1.0 \%(\%)^{b}$ & $78.3(56.8-92.4)$ & 0.47 \\
\hline $\mathrm{PaO}_{2}(\text { Torr })^{\mathrm{b}}$ & $85.2(62.3-137)$ & 0.15 \\
\hline
\end{tabular}

\section{Tumor factors}

Pathological stage ${ }^{c}$

III, IV

Histopathology

AIS

MIA

Lepidic

Acinar

Papillary

\section{Micropapillary}

Solid

Mucinous

Others

$\mathrm{Sq}$

Others

Pleural invasion ${ }^{\circ}$

Lymphovascular invasion ${ }^{\circ}$

CEA of $>5.0 \mathrm{ng} / \mathrm{mL}^{\mathrm{c}}$

Operative factors

Resected lobe ${ }^{\circ}$

RUL

RML

RLL

LUL

LLL

Lymph node dissection

Sampling ${ }^{\text {h }}$

Hilar'

Mediastinal

Complications ${ }^{\mathrm{c}, k}$

\section{Operation time (min)}

Bleeding $(\mathrm{mL})^{\mathrm{b}}$

Preoperative therapy ${ }^{\circ}$

Postoperative therapy ${ }^{\circ}$

a, Cox proportional hazard analyses were performed for continuous and categorical variables. ${ }^{b}$, continuous variables are presented as median (range). ${ }^{c}$, categorical variables are presented as number [percentage]. ${ }^{d}$, history of other cancers that were cured or were under control at the time of operation for lung cancer. ${ }^{e}$, stage I was significantly different from the other categories. ${ }^{f}$, adenocarcinoma in situ, minimal invasive adenocarcinoma and lepidic pattern predominant invasive adenocarcinoma had significantly better prognosis than the others. ${ }^{g}$, LUL was significantly associated with poor prognosis. ${ }^{h}$, non-systemic sampling of lymph nodes ' systemic dissection to the por the extent of upper or/and lower mediastinal lymph noc complications (all types and grades of short-term postoperative complications in the medical records). * , statistically significant. BI, Brinkman index; N, number; SMI, skeletal muscle index; BMI, body mass index; VC, vital capacity; \%VC, vital capacity percentage; FEV 1.0, forced expiratory volume in one second; $\mathrm{FEV} 1.0 \%$, forced expiratory volume in one second percentage; $\mathrm{PaO}_{2}$, partial pressure of oxygen in arterial blood; Ad, adenocarcinoma; AIS, adenocarcinoma in situ; MIA, minimally invasive adenocarcinoma; Sq, squamous cell carcinoma; CEA, carcinoembryonic antigen; LUL, left upper lobe; LLL, left lower lobe; RUL, right upper lobe; RML, right middle lobe; RLL, right lower lobe. 
Table S4 Clinicopathological characteristics and univariate analyses of mortality from postoperative six months in 391 males with Brinkman index $\geq 60$

\begin{tabular}{|c|c|c|}
\hline Variables & n (\%) or median (range) & $P$ value $^{a}$ \\
\hline SMI rate of change $(\%)^{\mathrm{b}}$ & $-3.68(-18.6$ to 14.7$)$ & $0.003^{*}$ \\
\hline Preoperative SMI $\left(\mathrm{cm}^{2} / \mathrm{m}^{2}\right)^{b}$ & $45.2(28.3-64.3)$ & 0.11 \\
\hline Postoperative SMI $\left(\mathrm{cm}^{2} / \mathrm{m}^{2}\right)^{b}$ & $43.3(27.2-63.5)$ & $0.007^{*}$ \\
\hline Preoperative BMI $\left(\mathrm{kg} / \mathrm{m}^{2}\right)^{\mathrm{b}}$ & $22.8(15.2-33.3)$ & $0.025^{\star}$ \\
\hline \multicolumn{3}{|c|}{ Patient factors and comorbidities } \\
\hline Age (years) ${ }^{b}$ & $69[43-87]$ & $0.002^{*}$ \\
\hline Brinkman index ${ }^{b}$ & $940[600-3,360]$ & $0.005^{*}$ \\
\hline Current smoker $^{\mathrm{C}}$ & $8[2]$ & 0.79 \\
\hline Albumin (mg/dL) ${ }^{b}$ & $4.2(2.8-5.0)$ & $0.003^{*}$ \\
\hline C-reactive protein $(\mathrm{ng} / \mathrm{mL})^{\mathrm{b}}$ & $0.13(0.01-15.4)$ & 0.64 \\
\hline Pulmonary disease $^{c}$ & $121[31]$ & $0.006^{\star}$ \\
\hline Interstitial pneumonitis $^{\mathrm{c}}$ & $25[6]$ & $0.002^{*}$ \\
\hline Cardiac disease $^{c}$ & $59[15]$ & 0.53 \\
\hline Arrhythmia ${ }^{c}$ & $26[7]$ & 0.84 \\
\hline Cerebrovascular disease $^{c}$ & $22[6]$ & 0.81 \\
\hline Diabetes mellitus $^{\mathrm{C}}$ & $74[19]$ & 0.88 \\
\hline Other cancers ${ }^{c, d}$ & $87[22]$ & $0.031^{*}$ \\
\hline \multicolumn{3}{|l|}{ Respiratory functions } \\
\hline VC $(L)^{b}$ & $3.44(1.85-5.16)$ & $0.0041^{*}$ \\
\hline$\%$ VC $(\%)^{b}$ & $103(60.9-151)$ & $0.04^{*}$ \\
\hline FEV $1.0(L)^{b}$ & $2.44(0.75-4.64)$ & $0.0008^{*}$ \\
\hline FEV $1.0 \%(\%)^{b}$ & $73.2(42.1-99.1)$ & $0.022^{*}$ \\
\hline $\mathrm{PaO}_{2}(\text { Torr })^{\mathrm{b}}$ & $83.4(59.2-164)$ & $0.0098^{*}$ \\
\hline
\end{tabular}

Tumor factors

Pathological stage ${ }^{c}$

$<0.0001^{* e}$

।

III, IV

Histopathology ${ }^{\circ}$

$\operatorname{Ad}$

AIS

MIA

Lepidic

Acinar

Papillary

Micropapillary

Solid

Mucinous

Others

$\mathrm{Sq}$

Others

Pleural invasion ${ }^{\circ}$

Lymphovascular invasion ${ }^{c}$

CEA of $>5.0 \mathrm{ng} / \mathrm{mL}^{\mathrm{c}}$

Operative factors

Resected lobe ${ }^{\circ}$

RUL

RML

RLL

LUL

LLL

254 [65]

92 [24]

45 [11]

237 [60]

6 [2]

3 [1]

52 [13]

77 [19]

23 [6]

5 [1]

51 [13]

9 [2]

12 [3]

101 [26]

53 [14]

137 [35]

209 [53]

124 [32]

0.0003

0.0001

142 [36]

64 [16]

111 [29]

55 [14]

Lymph node dissection

11 [3]

83 [21]

297 [76]

93 [24]

170 [68-467]

30 [little-2105]

Complications ${ }^{\mathrm{c}}$

0.37

Bleeding $(\mathrm{mL})$

$19[5]$

Preoperative therapy ${ }^{\circ}$

$126[32]$

$0.05^{\star}$

, Cox proportional hazard analyses were performed for continuous and categorical variables. ${ }^{b}$, continuous variables are presented as median (range). ${ }^{\circ}$, categorical variables are presented as number [percentage]. ${ }^{\text {d }}$, history of other cancers cured or under control at the time of operation for lung cancer. ${ }^{~}$, stage III \& IV was significantly different from the other categories. ${ }^{\prime}$, adenocarcinoma in situ, minimal invasive adenocarcinoma and lepidic pattern predominant invasive adenocarcinoma had significantly better prognosis than the others. 9 , non-systemic sampling of lymph nodes ${ }^{\mathrm{h}}$, systemic dissection to the extent of hilar lymph nodes ', systemic dissection to the extent of upper or/and lower mediastinal lymph nodes ${ }^{j}$, short-term postoperative complications (all types and grades of short-term postoperative complications in the medical records). * statistically significant $n$, number: SMI, skeletal muscle index; BMI, body mass index; VC, vita capacity; \%VC, vital capacity pers. ", FEV 1.0, for in second invasive adenocarcinoma; Sq, squamous cell carcinoma; CEA, carcinoembryonic antigen; LUL, left upper lobe; LLL, left lower lobe; RUL,
right upper lobe; RML, right middle lobe; RLL, right lower lobe. 
Table S5 Deaths in the four groups

\begin{tabular}{|c|c|c|c|c|}
\hline Variables & $\begin{array}{l}\text { Males with } \mathrm{BI} \geq 600 \\
\quad(\mathrm{~N}=391)\end{array}$ & $\begin{array}{l}\text { Males with } \mathrm{BI}<600 \\
\quad(\mathrm{~N}=225)\end{array}$ & $\begin{array}{l}\text { Females with } \mathrm{BI} \geq 600 \\
\qquad(\mathrm{~N}=34)\end{array}$ & $\begin{array}{l}\text { Females with } \mathrm{BI}<600 \\
\qquad(\mathrm{~N}=445)\end{array}$ \\
\hline Deaths & $110(28 \%)$ & $28(12 \%)$ & $6(18 \%)$ & $53(12 \%)$ \\
\hline \multicolumn{5}{|l|}{ Cause of death } \\
\hline Recurrence & 59 (54\%) & 17 (61\%) & $3(50 \%)$ & $34(64 \%)$ \\
\hline Respiratory disease & $20(18 \%)$ & $2(7 \%)$ & $1(17 \%)$ & $2(4 \%)$ \\
\hline Other cancers & $8(7 \%)$ & $3(11 \%)$ & 0 & $5(9 \%)$ \\
\hline Other diseases & $10(9 \%)$ & $1(3 \%)$ & 0 & $1(2 \%)$ \\
\hline Unknown & $13(12 \%)$ & $5(18 \%)$ & $2(33 \%)$ & $11(21 \%)$ \\
\hline Death without recurrence & $43(39 \%)$ & $10(36 \%)$ & $2(33 \%)$ & $16(30 \%)$ \\
\hline
\end{tabular}

BI, Brinkman index.

Table S6 Details of past histories of other cancers ${ }^{a}$

\begin{tabular}{lcc}
\hline Cancers & $\mathrm{N}(\%)^{\mathrm{b}}$ & $\mathrm{Pvalue}^{\mathrm{c}}$ \\
\hline Stomach & $32(8.3)$ & 0.08 \\
Head and neck and esophagus & $15(3.8)$ & 0.29 \\
Head and neck & $9(2.3)$ & 0.65 \\
Esophagus & $6(1.5)$ & 0.26 \\
Urinary system & $17(4.3)$ & 0.50 \\
$\quad$ Kidney & $8(2.0)$ & 0.64 \\
$\quad$ Urinary bladder & $9(2.3)$ & 0.62 \\
Colorectal & $18(4.6)$ & 0.33 \\
Prostate & $17(4.3)$ & 0.18 \\
The others & $10(2.6)$ & 1.0 \\
\hline
\end{tabular}

${ }^{a}$, these responses were obtained from 87 patients among 391 heavy-smoking males. Some patients had more than one response. ${ }^{b}$, percentage in relation to 391 heavy-smoking males; ${ }^{c}$, Fisher's exact test for the association with postoperative change of SMI $\leq-10 \%$. $\mathrm{N}$, number; SMI, skeletal muscle index.

Table S7 Association of additional procedures with operating time and postoperative sarcopenia

\begin{tabular}{|c|c|c|c|c|c|}
\hline \multirow[b]{2}{*}{ Additional procedures $^{a}$} & \multirow[b]{2}{*}{$\mathrm{N}$} & \multicolumn{2}{|c|}{ Operating time } & \multirow[b]{2}{*}{$P$ value ${ }^{d}$ for op time } & \multirow[b]{2}{*}{$P$ value ${ }^{e}$ for sarcopenia } \\
\hline & & $\begin{array}{c}\geq 200 \min (N=123) \\
N(\%)^{b}\end{array}$ & $\begin{array}{c}<200 \min (\mathrm{N}=268), \\
N(\%)^{c}\end{array}$ & & \\
\hline Partial resection & 39 & $18[15]$ & $21[8]$ & $0.046^{*}$ & 0.68 \\
\hline Segmentectomy & 10 & $5[4]$ & 5 [2] & 0.30 & 0.067 \\
\hline Bronchoplasty & 4 & 3 [2] & $1[<1]$ & 0.094 & 1.00 \\
\hline Arterioplasty & 16 & $11[9]$ & 5 [2] & $0.002^{*}$ & 0.74 \\
\hline Resection of adjacent organ & 32 & $21[17]$ & $11[4]$ & $<0.0001^{*}$ & 0.80 \\
\hline Resection of chest wall & 11 & $9[7]$ & $2[1]$ & $0.007^{\star}$ & 1.00 \\
\hline Any of the above & 89 & $50[41]$ & 39 [15] & $<0.0001^{*}$ & 1.00 \\
\hline
\end{tabular}

${ }^{a}$, these responses were obtained from 89 patients among 391 heavy-smoking males. Some patients had more than one additional procedures. ${ }^{b}$, percentage in relation to 123 patients; ${ }^{c}$, percentage in relation to 268 patients; ${ }^{d}$, Fisher's exact test for the association with operating time $\geq 200$ minutes. ${ }^{e}$, Fisher's exact test for the association with postoperative change of $\mathrm{SMI} \leq-10 \%$. ${ }^{*}$, statistically significant. $\mathrm{N}$, number; op, operation; SMI, skeletal muscle index. 